\title{
Effect of Pretreatments on Seed Germination of Prunus mahaleb L.
}

\author{
Elias PIPINIS ${ }^{1 *}$, Elias MILIOS², Olga MAVROKORDOPOULOU', Christina \\ GKANATSIOU ${ }^{1}$, Maria ASLANIDOU $^{1}$, Pavlos SMIRIS' \\ ${ }^{1}$ Aristotle University of Thessaloniki, Faculty of Forestry and Natural Environment, Laboratory of \\ Silviculture, 54124 Thessaloniki, Greece; epipinis@for.auth.gr (*orresponding author) \\ ${ }^{2}$ Democritus University of Thrace, Department of Forestry and Management of the Environment \\ and Natural Resources, Pandazidou 193, 68200, Orestiada, Greece
}

\begin{abstract}
Sexual propagation of Prunus mahaleb is difficult due to seed dormancy. To overcome dormancy and maximize germination, various pretreatments have been applied, including stratification (warm and cold), gibberellic acid ( $\left.\mathrm{GA}_{3}\right)$, sulfuric acid scarification (AS), and endocarp removal. The results show that warm stratification (WS) prior to cold stratification (CS) does not improve seed germination and a long period of WS ( 3 months) is disastrous for germination. CS alone (up to 4 months) has been found to hasten and increase seed germination. Pretreatment of the seeds with exogenous $\mathrm{GA}_{3}$, during the CS period, has been observed to result in significantly higher seed germination. AS of seeds for 45 minutes prior to GA 3 (1000 ppm for 24 hours) plus CS (up to 1 month) pretreatment has been considered to reduce the mechanical resistance of endocarp and improve germination. However, extended time of AS (180 minutes) prior to GA 3 plus CS pretreatment has been found to harm the seeds. The removal of endocarp has been noted to significantly improve germination. Seeds without endocarp, which were pretreated with GA 3 (1000 or 2000 ppm for 24 hours) and then cold stratified for 1 month, have been noted to exhibit the highest germination percentages.
\end{abstract}

Keywords: acid scarification, dormancy, endocarp, gibberellic acid, stratification

\section{Introduction}

Prunus mahaleb L., commonly known as the mahaleb cherry, is a member of the Rosaceae family. The species mainly occurs in the submediterranean zone of southern and central Europe, south-western Asia, and northwest Africa (Jordano and Schupp, 2000; Kollmann and Pflugshaupt, 2005). It is a small tree, usually $2-10 \mathrm{~m}$, which occurs scattered as single individuals or in small groups in a great altitudinal range and grows in sunny places as well as in dry and stony soils (Browicz, 1982). P. mahaleb is cultivated for ornamental use because of its attractive flowers (Browicz, 1982), and is also used in reforestation of areas because this species is useful for wood production and to wildlife (Grisez et al., 2008). However, it is widely used as a rootstock because of its ability to grow well on dry and rocky areas, as well as its high resistance to pests (Al-Absi, 2010; Patton et al., 1997).

P. mahaleb could be propagated in nurseries using seeds because this method is cost-effective (Macdonald, 2006). However, this propagation technique exhibits difficulty due to seed dormancy. Many Prunus species, including the seeds of $P$. mahaleb, have two different types of dormancy: internal or embryo dormancy and external or endocarp dormancy (Ghayyad et al., 2010; Martinez-Gomez and Dicenta, 2001; Mehanna and Martin, 1985).
Various pretreatments have been used by scientists to overcome seed dormancy of Prunus seeds, with stratification being the most common. Prolonged cold or warm plus cold stratification is needed to overcome the seed dormancy of most Prunus species (Dirr and Heuser, 1987; Grisez et al., 2008). The effect of warm plus cold stratification pretreatment on germination varies among the species of Prunus (Piotto et al., 2003). According to Iliev et al. (2012), a 6-week warm stratification (WS) period prior to a 5 -month cold stratification (CS) period is effective in increasing seed germination of $P$. avium stored seeds. Similarly, the effective pretreatment that maximizes germination of $P$. campanulata seeds is 4-6 weeks of WS, followed by 8 weeks of CS (Chen et al., 2007). According to Grisez et al. (2008), seed germination in seven species of Prunus (P. armeniaca, $P$. avium, $P$. domestica, $P$. mabaleb, $P$. padus, $P$. pensylvanica, and $P$. serotina) has been noted to be much higher after WS plus CS than after CS only. Ghayyad et al. (2010) suggested that alternate stratification (cold-warmcold) is more effective than 10 weeks of continuous CS in germination of $P$. mahaleb seeds. In contrast, Lockley (1980) achieved the best results in germination of $P$. virginiana after 16 weeks of CS only. International Seed Testing Association (1999) suggests 3 to 4 months of CS (3$5^{\circ} \mathrm{C}$ ) for the seeds of $P$. avium, P. padus, and P. serotina.

The presence of a stony endocarp in Prunus fruits, which is water permeable (Dirr and Heuser, 1987), may 
184

restrict seed germination (Young and Young, 1992). However, Nikolaeva (1969, 1977 as referenced in Baskin and Baskin, 1998), after her research on stony endocarps fruits, concluded that the endocarp does not mechanically restrict germination. When the embryo dormancy is broken by CS pretreatment, then the embryo has enough growth potential to break the endocarp. The removal of endocarp was found to hasten or increase the germination in $P$. avium (Cetinbas and Koyuncu, 2006), P. dulcis (Garcia - Gusano et al., 2004), and P. mahaleb (Ghayyad et al., 2010).

Gibberellin's applications have been reported to be effective in partially substituting for the CS requirement in Prunus seeds in which the endocarp had been removed (Grisez et al., 2008). Cetinbas and Koyuncu (2006) suggested the endocarp removal of cold-stratified seeds and subsequent gibberellic acid $\left(\mathrm{GA}_{3}\right)$ application to break the dormancy and increase germination of $P$. avium seeds. Ghayyad et al. (2010) obtained the best results in germination of $P$. mahaleb seeds by removing the endocarp and then applying $\mathrm{GA}_{3}$. Also, exogenous applications of $\mathrm{GA}_{3}$ and $\mathrm{H}_{2} \mathrm{O}_{2}$ prior to $\mathrm{CS}$ have been reported to improve germination in Prunus species seeds without endocarp (Imani et al., 2011; Zeinalabedini et al., 2009).

In the published literature, there is no description concerning the effect of WS prior to CS on the germination of $P$. mahaleb seeds. Also, the effect of exogenous $\mathrm{GA}_{3}$ in seed germination when it is applied during the CS of seeds has not been studied.

The objectives of the present study were to: i) examine the effectiveness of WS, CS, GA, sulfuric acid scarification (AS), and endocarp removal pretreatments on germination; ii) describe the effects of WS and CS pretreatment combinations on germination; iii) describe the effects of $\mathrm{GA}_{3}$ and CS pretreatment combinations on germination; iv) describe the effects of AS, GA, and CS pretreatment combinations on germination; $\mathrm{v}$ ) describe the effects of $\mathrm{GA}_{3}$ and CS pretreatment combinations on germination of seeds without endocarp; and vi) propose effective pretreatments that maximize germination of $P$. mahaleb seeds.

\section{Materials and methods}

Mature fruits of $P$. mahaleb were collected on 18 July 2009 from a number of trees (more than 10) growing in their natural habitat $\left(40^{\circ} 21^{\prime} 20^{\prime \prime}\right.$ ' N, 21 $1^{\circ} 55^{\prime} 58^{\prime}$ ' E, $690 \mathrm{~m}$ elevation) in northern Greece. After collection, the fruits were pulped by hand and the pulp (exocarp and mesocarp) was removed with water. Then, the clean seeds (with endocarp) that sunk to the bottom of the container were spread out on filter papers in laboratory conditions and left to dry. After drying, the seeds were stored in glass containers in refrigerator $\left(3-5^{\circ} \mathrm{C}\right)$ until used in the experiments. In this study, the term "seed" refers to the true seed plus endocarp.

\section{Seed pretreatment}

Germination experiments were started the following October and conducted in the laboratory of Silviculture, Faculty of Forestry and Natural Environment, Aristotle University of Thessaloniki.

\section{Effect of WS and CS on germination}

The seeds were mixed with moist sterilized river sand in plastic containers and warm stratified for 1,2, or 3 months at $20-25^{\circ} \mathrm{C}$ (there were three plastic containers). At the end of each WS period (1,2, and 3 months), the plastic containers were placed in the refrigerator $\left(3-5^{\circ} \mathrm{C}\right)$ for the seeds to be subjected to CS for $0,1,2,3$, or 4 months. In total, 15 pretreatments (combinations between WS and CS) were applied.

\section{Effect of $\mathrm{GA}_{3}$ and $C S$ on germination}

The seeds were mixed with sterilized river sand and placed in three plastic containers. The sand of each plastic container was moistened with 500,1000 , or $2000 \mathrm{ppm}$ $\mathrm{GA}_{3}$. Then, the three plastic containers were subjected to $\operatorname{CS}\left(3-5^{\circ} \mathrm{C}\right)$ for $1,2,3$, or 4 months. Nonstratified seeds (0 month of CS) were treated with GA solutions ( 500 , 1000 , and $2000 \mathrm{ppm}$ ) for 48 hours and then placed to germinate in growth chamber. In total, 15 pretreatments (combinations between $\mathrm{GA}_{3}$ and CS) were applied. During CS, sand moisture was checked periodically and GA solution was added whenever necessary to keep it moist.

Moreover, in the frame of the above-mentioned experiments, seeds that were not warm stratified (0 month WS) or not treated with $\mathrm{GA}_{3}(0 \mathrm{ppm})$ were placed with moist, sterilized river sand in a plastic container and subjected to CS only for $0,1,2,3$, or 4 months.

\section{Effect of $\mathrm{GA}_{3}$ and $C S$ on germination of acid scarified seeds}

The seeds were immersed in concentrated (95-97\%) sulfuric acid for 45, 90, and 180 minutes. Acid-scarified seeds were treated with 1000 ppm of $\mathrm{GA}_{3}$ for 48 hours and then mixed with moist, sterilized river sand in plastic containers and cold stratified for $0,1,2,3$, or 4 months at $3-5^{\circ} \mathrm{C}$. There were three plastic containers that corresponded to the three durations of AS. In total, 15 pretreatments (combinations between AS plus 1000 ppm GA and CS) were applied.

\section{Effect of $\mathrm{GA}_{3}$ and $C S$ on germination of seeds without endocarp}

Seeds with their endocarp removed manually were treated with 0 (distilled water), 500, 1000, and $2000 \mathrm{ppm}$ $\mathrm{GA}_{3}$ for 24 hours. Subsequently, the true seeds were mixed with moist, sterilized river sand in plastic containers and cold stratified for $0,1,2,3$, or 4 months at $3-5^{\circ} \mathrm{C}$. There were four plastic containers that corresponded to the four concentrations of $\mathrm{GA}_{3}$. In total, 20 pretreatments (combinations between $\mathrm{GA}_{3}$ and $\mathrm{CS}$ ) were applied. 
During stratification, sand moisture was checked periodically and distilled water (in experiments where $\mathrm{GA}_{3}$ was not applied during the CS period) was added whenever necessary to keep it moist.

\section{Germination test}

In each of the above-mentioned experiments, at the end of the CS period, a random sample of 100 seeds was taken out from each plastic container and randomly placed in four plastic Petri dishes ( 25 seeds per Petri dish). For each pretreatment, there were four replications of 25 seeds. The seeds were placed on sterilized river sand, moistened with distilled water, in 9-cm plastic Petri dishes. Prior to the arrangement of seeds in Petri dishes, they were dusted with fungicide (Captan) to avoid fungi development. The Petri dishes were randomly arranged on the shelves of the growth chamber and watered as needed with distilled water. The temperature in the growth chamber was set at $20^{\circ} \mathrm{C}$ for a 16 -hour dark period and $25^{\circ} \mathrm{C}$ for an 8 -hour light period. Germinated seeds were counted each week for 9 weeks. A seed with at least 2-mm-long radicle was considered to be germinated (I.S.T.A., 1999). Finally, for each treatment, the germination percentage (GP) and the mean germination time (MGT) were calculated as the average of the four replications. The MGT was calculated for each replication per treatment according to the following equation:

\section{$\mathrm{MGT}=\Sigma(\mathrm{Dn}) / \Sigma \mathrm{n}$}

where $n$ is the number of seeds that germinated on day $D$ and $D$ is the number of days counted from the beginning of the test (Ellis and Roberts, 1981).

\section{Statistical analysis}

In all the experiments, a completely randomized experimental design was used. In each experiment, pretreatment combinations in which none of the seeds germinated were not included in the statistical analysis. The GP data were arc-sine square root transformed before analysis (Snedecor and Cochran, 1980). The transformed data were checked for normality and homogeneity of variances and then analyzed by one-way ANOVA, and comparisons of the means were made using the Duncan test (Klockars and Sax, 1986). All statistical analyses were carried out using SPSS 12.0 (SPSS, Inc., USA).

\section{Results and discussion}

\section{Effect of WS and CS on germination}

There were significant differences in GPs $(\alpha=0.05)$ among the combinations of WS and CS periods $\left(\mathrm{F}_{12,39}=\right.$ $15.83, p=0.000$ ).

None of the P. mabaleb seeds subjected to only WS for 1,2 , or 3 months germinated (Tab. 1). On the other hand, in seeds subjected to 0 or 1 month of WS, a significant increase $(p<0.05)$ in GP was observed with the increase in CS duration, except for one case. An increase in the CS period from 2 to 3 months in seeds that had been warm stratified for 1 month did not induce significant increase in GP $(p>0.05)$. According to the results of this experiment, a rather high GP $(33 \%)$ was observed after only a 4-month CS period that did not differ significantly $(p>0.05)$ with the GP (24\%) of 1-month WS plus 4-month CS pretreatment. Ghayyad et al. (2010) found that seed germination of $P$. mahaleb was $3.33 \%$ after a 10 -week stratification period at $2-4^{\circ} \mathrm{C}$ and $5.33 \%$ after alternate stratification (4 weeks of cold plus 2 weeks of warm plus 4 weeks of cold).

Long WS period (3 months), prior to CS, was disastrous for seed germination. On the contrary, other Prunus species germination was found to be favored by WS pretreatment. Suszka (1967) obtained the best GP with respect to the seeds of $P$. serotina when a 2 -week warm period prior to a 189-day cold period was employed. Similarly, Chen et al. (2007) found that intact P. campanulata seeds require 4-6 weeks of WS, followed by 8 weeks of CS to obtain maximum GP. Macdonald (2006) reported that seeds with a hard endocarp require WS to break it down.

In treatments without WS, MGT was observed to exhibit a decrease trend when the duration of CS period was increased. A similar trend in MGT was observed by AlAbsi (2010), who used only CS in one of his experiments for germination of $P$. mahaleb seeds. However, the MGT obtained in our study, after only a 3-month CS period, is lower than that found in the study by Al-Absi (2010). This difference may be due to different germination condi-

Tab. 1. Effect of WS combined with CS on GP and MGT of $P$. mahaleb

\begin{tabular}{|c|c|c|}
\hline $\begin{array}{c}\text { WS } \\
\text { (months) }\end{array}$ & $\begin{array}{c}\text { CS } \\
\text { (months) }\end{array}$ & $\begin{array}{c}\text { Germinated seeds } \\
\text { GP }( \pm \text { S.D. }), \text { MGT in days }( \pm \text { S.D. })\end{array}$ \\
\hline \multirow{5}{*}{0} & 0 & 0.00 \\
\hline & 1 & $2.00 \mathrm{fg}( \pm 2.31),{ }^{*}$ \\
\hline & 2 & $12.00 \mathrm{~cd}( \pm 3.27), 14.29( \pm 2.41)$ \\
\hline & 3 & $20.00 \mathrm{~b}( \pm 5.66), 10.62( \pm 1.23)$ \\
\hline & 4 & $33.00 \mathrm{a}( \pm 3.83), 9.46( \pm 1.00)$ \\
\hline \multirow{5}{*}{1} & 0 & 0.00 \\
\hline & 1 & $2.00 \mathrm{fg}( \pm 2.31),{ }^{*}$ \\
\hline & 2 & $7.00 \mathrm{de}( \pm 3.83), 15.46( \pm 1.75)$ \\
\hline & 3 & $11.00 \mathrm{~cd}( \pm 5.03), 7.44( \pm 0.88)$ \\
\hline & 4 & $24.00 \mathrm{ab}( \pm 5.66), 7.22( \pm 0.44)$ \\
\hline \multirow{5}{*}{2} & 0 & 0.00 \\
\hline & 1 & $2.00 \mathrm{fg}( \pm 2.31),{ }^{*}$ \\
\hline & 2 & $7.00 \mathrm{de}( \pm 3.83), 7.58( \pm 1.17)$ \\
\hline & 3 & $5.00 \operatorname{def}( \pm 2.00), 9.63( \pm 3.35)$ \\
\hline & 4 & $4.00 \mathrm{efg}( \pm 3.27), 8.75( \pm 3.50)$ \\
\hline \multirow{5}{*}{3} & 0 & 0.00 \\
\hline & 1 & 0.00 \\
\hline & 2 & 0.00 \\
\hline & 3 & $1.00 \mathrm{~g}( \pm 2.00),{ }^{*}$ \\
\hline & 4 & 0.00 \\
\hline
\end{tabular}

Note: Means are statistically different at $p<0.05$, when they share no common letter. The comparisons were made using the Duncan test; ${ }^{*}$ MGT was not calculated because in one of the four replications, no seed germinated 
186

tions. In Al-Absi's (2010) research, seed germination was conducted under greenhouse conditions.

\section{Effect of $\mathrm{GA}_{3}$ and $C S$ on germination}

There were significant differences in GPs $(\alpha=0.05)$ among the combinations of CS periods and $\mathrm{GA}_{3}$ concentrations $\left(\mathrm{F}_{18.57}=79.57, p=0.000\right)$.

$\mathrm{GA}_{3}$ application during seed CS not only appeared to shorten the required CS period, but also significantly improve GP (Tab. 2) of $P$. mahaleb. Exogenous GA applications have been reported to be effective in breaking dormancy and substituting for the CS requirement in seeds of many species (Karam and Al-Salem, 2001; Pipinis et al., 2011a; 2012; Smiris et al., 2006).

It is obvious (Tab. 2) that the endocarp of $P$. mahaleb fruit was permeable to $\mathrm{GA}_{3}$ because there were significant differences $(p<0.05)$ in germination after the five periods $\left(0,1,2,3\right.$, and 4 months) of CS among $\mathrm{GA}_{3}$-treated and untreated seeds. This finding is in agreement with that observed by Dirr and Heuser (1987), who reported that the stony endocarp in Prunus fruits is water permeable.

Germination of $\mathrm{GA}_{3}$ (2000 ppm)-treated seeds during 1-month of CS was equal to that of seeds subjected to only 4 months of CS. Pretreatments of seeds with 500 and 1000 ppm GA, during the 4 months of CS, gave the highest GPs $(p<0.05)$ of 69 and $76 \%$, respectively. Al-Absi (2010) also achieved a 65\% GP for P. mahaleb by treating the seeds, which were previously cold stratified for 3

Tab. 2. Effect of GA $\mathrm{G}_{3}$ combined with CS on GP and MGT of P. mahaleb

\begin{tabular}{|c|c|c|}
\hline $\begin{array}{c}\mathrm{GA}_{3} \\
(\mathrm{ppm})\end{array}$ & $\begin{array}{c}\text { CS } \\
\text { (months) }\end{array}$ & $\begin{array}{c}\text { Germinated seeds } \\
\mathrm{GP}( \pm \text { S.D. }), \text { MGT in days }( \pm \text { S.D. })\end{array}$ \\
\hline \multirow{5}{*}{0} & 0 & 0.00 \\
\hline & 1 & $2.00 \mathrm{j}( \pm 2.31),{ }^{*}$ \\
\hline & 2 & $12.00 \mathrm{~h}( \pm 3.27), 14.29( \pm 2.41)$ \\
\hline & 3 & $20.00 \mathrm{~g}( \pm 5.66), 10.62( \pm 1.23)$ \\
\hline & 4 & $33.00 \mathrm{f}( \pm 3.83), 9.46( \pm 1.00)$ \\
\hline \multirow{5}{*}{500} & 0 & $1.00 \mathrm{j}( \pm 2.00)^{*}$ \\
\hline & 1 & $11.00 \mathrm{~h}( \pm 3.83), 17.50( \pm 2.86)$ \\
\hline & 2 & 38.00 ef $( \pm 5.16), 13.76( \pm 1.33)$ \\
\hline & 3 & $55.00 \mathrm{~b}( \pm 5.03), 9.99( \pm 1.30)$ \\
\hline & 4 & $69.00 \mathrm{a}( \pm 6.00), 8.86( \pm 1.18)$ \\
\hline \multirow{5}{*}{1000} & 0 & $1.00 \mathrm{j}( \pm 2.00),{ }^{*}$ \\
\hline & 1 & $17.00 \mathrm{gh}( \pm 6.00), 18.20( \pm 2.12)$ \\
\hline & 2 & $44.00 \mathrm{cde}( \pm 5.66), 14.23( \pm 1.79)$ \\
\hline & 3 & $54.00 \mathrm{bc}( \pm 6.93), 9.15( \pm 0.90)$ \\
\hline & 4 & $76.00 \mathrm{a}( \pm 5.66), 9.05( \pm 1.16)$ \\
\hline \multirow{5}{*}{2000} & 0 & $5.00 \mathrm{i}( \pm 2.00), 23.63( \pm 3.35)$ \\
\hline & 1 & $33.00 \mathrm{f}( \pm 6.83), 18.44( \pm 2.22)$ \\
\hline & 2 & $42.00 \operatorname{def}( \pm 5.16), 13.63( \pm 0.82)$ \\
\hline & 3 & $49.00 \mathrm{bcd}( \pm 6.00), 10.81( \pm 1.18)$ \\
\hline & 4 & $58.00 \mathrm{~b}( \pm 5.16), 9.01( \pm 0.72)$ \\
\hline
\end{tabular}

Note: Means are statistically different at $p<0.05$, when they share no common letter. The comparisons were made using the Duncan test; ${ }^{*}$ MGT was not calculated because in one of the four replications, no seed germinated months, with 1000 ppm GA. The exogenous GA application is considered to increase the growth potential of the embryo to break the resistance of the endocarp. According to Carpita et al. (1983) and Rascio et al. (1998), pretreatment of seeds with $\mathrm{GA}_{3}$ results in an increase in the growth potential of the embryo.

Also, the results indicate that the MGT values of untreated and $\mathrm{GA}_{3}$-treated seeds cold stratified for 2, 3, and 4 months were more or less the same. However, Al-Absi (2010) stated that CS followed by GA pretreatment significantly improved the MGT of $P$. mahaleb seeds.

\section{Effect of $\mathrm{GA}_{3}$ and $C S$ on germination of acid-scarified seeds}

There were significant differences in GPs $(\alpha=0.05)$ among the combinations of AS and CS periods $\left(\mathrm{F}_{14,45}=\right.$ $46.27, p=0.000)$

The GPs of cold-stratified seeds for up to 1 month that had been acid scarified for 45 minutes and pretreated with $\mathrm{GA}_{3}(1000 \mathrm{ppm})$ for 24 hours (27 and 32\%, Tab. 3) were higher than those of previous experiment where seeds were cold stratified for the same period and pretreated with 1000 ppm GA (during CS) (1 and 17\%, Tab. 2). Also, the GPs of seeds that were only cold stratified for up to 1 month (in the first experiment) were very low (0 and $2 \%$, Tab. 1). These findings indicate that AS of seeds for 45 minutes prior to $\mathrm{GA}_{3}$ (1000 ppm) plus CS (up to 1 month) pretreatment was effective in germination (probably by reducing the mechanical resistance of the endocarp), and also that the endocarp is an obstacle in the germination of $P$. mahaleb seeds. Sulfuric acid has been used in the scarification method to break seed coat dormancy in many species (Pipinis et al., 2011a; 2011b; Sacheti and Al-Rawahy, 1998). In contrast, Grisez et al. (2008) stated that scarification with sulfuric acid to break or soften the endocarp had no effect or negative effect on seed germination of Prunus species. Also, Gercekcioglu and Cekic (1999) reported that chemical scarification is ineffective in overcoming dormancy in $P$. mahaleb seeds.

In each CS period, in almost all cases, the increase in AS duration resulted in a significant decrease $(p<0.05)$ in seed germination. A similar trend was observed by Ghayyad et al. (2010). As the endocarp of Prunus fruits is permeable to water (Dirr and Heuser, 1987), the long duration of AS treatment of $P$. mahaleb seeds may cause seed damage.

According to the results of our study, the combination of AS ( 45 minutes), $\mathrm{GA}_{3}$ ( $1000 \mathrm{ppm}$ for 24 hours), and CS (3 months) pretreatments gave the higher GP $(48 \%)$ that did not differ significantly ( $p>0.05)$ from the GP (42\%) of the combination of AS ( 45 minutes), $\mathrm{GA}_{3}(1000 \mathrm{ppm}$ for 24 hours), and a 4-month CS period pretreatments. AlAbsi (2010), using shorter durations of AS (10, 20, and 30 minutes) in $P$. mahaleb seeds that had been cold stratified for 2 and 3 months, achieved GPs from 40 to 48.3\%. According to Ghayyad et al. (2010), after 10 weeks of CS, the P. mahaleb seeds that had been acid scarified for $10 \mathrm{~min}$ - 
utes gave higher GP (15.33\%) than nonscarified seeds or seeds scarified for 20 and 40 minutes.

In each AS pretreatment, the increase in CS period led to a gradual decrease in MGT. Also, the results indicate that the increase in AS duration from 45 to 90 minutes prior to CS ( $0,1,2,3$, and 4 months) of seeds led to similar MGT values. Al-Absi (2010) reported that AS of $P$. mahaleb seeds for various durations (10, 20, and 30 minutes), which had been stratified for 0,1 , and 3 months, did not significantly change the MGT; however, only in seeds that had been stratified for 2 months, the increase in AS duration from 10 to 20 and 30 minutes significantly decreased the MGT.

\section{Effect of $G A_{3}$ and $C S$ on germination of seeds without endocarp}

There were significant differences in GPs of seeds without endocarp $(\alpha=0.05)$ among the combinations of $\mathrm{GA}_{3}$ concentrations and CS periods $\left(\mathrm{F}_{8,27}=48.44, p=0.000\right)$.

Control seeds ( 0 ppm GA 3 plus 0 month of CS) without endocarp germinated at a percentage of $22 \%$ (Tab. 4). Similar GPs (27 and 20\%, Tab. 3) were observed in the previous experiment in seeds that were only subjected to a combination of AS (for 45 or 90 minutes) and $\mathrm{GA}_{3}$ (1000 ppm for 24 hours) pretreatments. In contrast, in the first and second experiments, non-cold-stratified seeds (with endocarp) that were subjected to WS $(0,1$, 2 , and 3 months) or $\mathrm{GA}_{3}(0,500,1000$, and $2000 \mathrm{ppm})$ pretreatments did not germinate (Tab. 1) or germinated at low percentages $(0-5 \%, T a b .2)$, respectively. Increase in the CS period of the removed endocarp seeds $(0 \mathrm{ppm}$ $\mathrm{GA}_{3}$ ) to 1 and 2 months resulted in significant increased

Tab. 3. Effects of $\mathrm{GA}_{3}$ combined with CS on GP and MGT of acid-scarified $P$. mahaleb seeds

\begin{tabular}{|c|c|c|c|}
\hline $\begin{array}{c}\text { AS } \\
\text { (minutes) }\end{array}$ & $\begin{array}{c}\mathrm{GA}_{3} \\
(\mathrm{ppm})\end{array}$ & $\begin{array}{c}\text { CS } \\
\text { (months) }\end{array}$ & $\begin{array}{c}\text { Germinated seeds } \\
\text { GP }( \pm \text { S.D.), MGT } \\
\text { in days ( } \pm \text { S.D.) }\end{array}$ \\
\hline \multirow{5}{*}{45} & \multirow{5}{*}{1000} & 0 & $27.00 \mathrm{de}( \pm 5.03), 22.90( \pm 2.51)$ \\
\hline & & 1 & $32.00 \mathrm{~cd}( \pm 4.62), 22.31( \pm 2.57)$ \\
\hline & & 2 & $23.00 \mathrm{e}( \pm 3.83), 13.46( \pm 1.30)$ \\
\hline & & 3 & $48.00 \mathrm{a}( \pm 5.66), 13.30( \pm 1.70)$ \\
\hline & & 4 & $42.00 \mathrm{ab}( \pm 5.16), 9.14( \pm 1.15)$ \\
\hline \multirow{5}{*}{90} & \multirow{5}{*}{1000} & 0 & $20.00 \mathrm{e}( \pm 5.66), 22.05( \pm 2.84)$ \\
\hline & & 1 & $22.00 \mathrm{e}( \pm 5.16), 22.24( \pm 2.28)$ \\
\hline & & 2 & $11.00 \mathrm{f}( \pm 3.83), 13.13( \pm 1.75)$ \\
\hline & & 3 & $36.00 \mathrm{bc}( \pm 6.53), 12.71( \pm 0.97)$ \\
\hline & & 4 & $37.00 \mathrm{bc}( \pm 5.03), 9.27( \pm 1.14)$ \\
\hline \multirow{5}{*}{180} & \multirow{5}{*}{1000} & 0 & $8.00 \mathrm{fg}( \pm 3.27), 24.21( \pm 2.92)$ \\
\hline & & 1 & $5.00 \mathrm{gh}( \pm 2.00), 16.63( \pm 3.35)$ \\
\hline & & 2 & $3.00 \mathrm{~h}( \pm 2.00), 16.33( \pm 4.04)$ \\
\hline & & 3 & $5.00 \mathrm{gh}( \pm 2.00), 13.13( \pm 1.75)$ \\
\hline & & 4 & $1.00 \mathrm{i}( \pm 2.00),{ }^{*}$ \\
\hline
\end{tabular}

Note: Means are statistically different at $p<0.05$, when they share no common letter. The comparisons were made using the Duncan test; ${ }^{*}$ MGT was not calculated as in one of the 4 replication no seed germinated
GPs $(p<0.05)$ of 44 and $90 \%$, respectively. In the first experiment, seeds subjected only to CS for 1 and 2 months exhibited GPs of 2 and 12\%, respectively (Tab. 1). These results confirm that the endocarp plays a major role in $P$. mahaleb seeds dormancy and its removal significantly improves germination. It is most likely that the endocarp inhibits germination by imposing mechanical resistance to the emergence of the radicle. According to Cetinbas and Koyuncu (2006), removal of the endocarp after CS has a positive effect on the germination of $P$. avium seeds. Chen et al. (2007) reported that $25 \%$ of nonstratified $P$. campanulata seeds without endocarp germinated in 21 days. Also, Tewari et al. (2011) found that the removal of seed coat in $P$. cerasoides seeds greatly increased germination. In contrast, Ghayyad et al. (2010) noted that only $4.33 \%$ of nonstratified P. mahaleb seeds without endocarp germinated and $21 \%$ of the seeds without endocarp that were subjected to a 10 -week alternate stratification period ( 4 weeks at $2-4^{\circ} \mathrm{C}$ plus 2 weeks at $20-25^{\circ} \mathrm{C}$ plus 4 weeks at $2-4^{\circ} \mathrm{C}$ ) germinated.

The results of this experiment show that the $\mathrm{GA}_{3}$ application on seeds, whose endocarp was removed prior to CS, resulted in further improvement in seed germination. After 0 and 1 month of CS, the seeds that had been pretreated with $\mathrm{GA}_{3}(500,1000$, or $2000 \mathrm{ppm})$ exhibited higher GPs $(p<0.05)$ than those that were not pretreated with $\mathrm{GA}_{3}$. A similar trend was observed by Gercekcioglu and Cekic (1999). Also, the germination of $\mathrm{GA}_{3}$ pretreated seeds (for each concentration) undergoing 1 month of $\mathrm{CS}$ was higher than that of seeds that were only pretreated with $\mathrm{GA}_{3}$. However, a longer than 1-month CS period of $\mathrm{GA}_{3}$ pretreated seeds could not be used because towards the end of 1 month of CS, the seeds began to germinate. The combination of $\mathrm{CS}$ with $\mathrm{GA}_{3}$ pretreatment has been reported to improve germination in P. communis, P. haussknechtii, and P. persica seeds without endocarp (Imani et al., 2011). Cetinbas and Koyuncu (2006) found that $\mathrm{GA}_{3}$ pretreatment of endocarp-removed $P$. avium seeds after CS positively affected germination. On the other hand, Ghayyad et al. (2010) reported that the $\mathrm{GA}_{3}$ pretreatment alone gave better results with respect to germination of $P$. mahaleb seeds without endocarp, than the GA 3 pretreatment followed by a 10 -week period of CS. Also, Zeinalabedini $e t$ al. (2009) observed that the combination of stratification $\left(\right.$ at $4^{\circ} \mathrm{C}$ ) with $\mathrm{GA}_{3}$ pretreatment (1000 ppm for $30 \mathrm{~min}$ utes) did not improve germination of seeds without endocarp in three wild almonds species. This difference may be due to the different time of GA pretreatment. In our study, $P$. mahaleb seeds without endocarp were pretreated with GA for 24 hours, in contrast to the method followed by Zeinalabedini et al. (2009), who pretreated seeds of the three wild almonds species without endocarp with $\mathrm{GA}_{3}$ for 30 minutes.

In the endocarp-removed seeds, $\mathrm{GA}_{3}(2000 \mathrm{ppm})$ application appeared to entirely replace the need for CS. The germination of nonstratified seeds that were only pretreat- 
188

Tab. 4. Effect of GA $\mathrm{G}_{3}$ combined with CS on GP and MGT of $P$. mahaleb seeds without endocarp

\begin{tabular}{ccc}
\hline $\begin{array}{c}\mathrm{GA}_{3} \\
(\mathrm{ppm})\end{array}$ & $\begin{array}{c}\mathrm{CS} \\
\text { (months })\end{array}$ & $\begin{array}{c}\text { Germinated seeds } \\
\text { GP } \pm \text { S.D. }), \text { MGT in days }( \pm \text { S.D. })\end{array}$ \\
\hline \multirow{2}{*}{0} & 0 & $22.00 \mathrm{f}( \pm 5.16), 16.93( \pm 2.22)$ \\
& 1 & $44.00 \mathrm{e}( \pm 5.66), 16.89( \pm 3.41)$ \\
\hline \multirow{2}{*}{500} & 2 & $90.00 \mathrm{bc}( \pm 5.16), 14.18( \pm 1.03)$ \\
\hline \multirow{2}{*}{1000} & 0 & $61.00 \mathrm{~d}( \pm 3.83), 12.77( \pm 1.53)$ \\
& 1 & $85.00 \mathrm{c}( \pm 5.03), 9.67( \pm 1.82)$ \\
\hline \multirow{2}{*}{2000} & 0 & $71.00 \mathrm{~d}( \pm 5.03), 11.16( \pm 1.73)$ \\
& 1 & $95.00 \mathrm{ab}( \pm 5.03), 8.28( \pm 1.26)$ \\
\hline
\end{tabular}

Note: Means are statistically different at $p<0.05$, when they share no common letter. The comparisons were made using the Duncan test

ed with $2000 \mathrm{ppm}$ of $\mathrm{GA}_{3}$ was as high as the germination of seeds (90\%) that were only subjected to 2 months of CS (Tab. 4). According to Ghayyad et al. (2010), P. mahaleb seeds without endocarp, which were pretreated only with 1250 ppm GA 3 exhibited a GP of 70\%.

$\mathrm{GA}_{3}$ pretreatment of seeds hastened germination. The MGT of seeds subjected only to CS for 0 and 1 month was 16.93 and 16.89 days, respectively, whereas that of seeds that were pretreated with $\mathrm{GA}_{3}$ and then stratified for 0 and 1 month of CS ranged from 7.80 to 12.77 days.

\section{Conclusions}

Based on the results of this study, it can be concluded that WS prior to CS did not improve germination of $P$. mahaleb seeds. However, a 3-month period of WS prior to CS brought about a dramatic reduction in seed germination. Similarly, extended time of AS (180 minutes) prior to $\mathrm{GA}_{3}$ plus CS pretreatment was found to be harmful to the seeds. However, $\mathrm{GA}_{3}$ application during CS pretreatment or AS for 45 minutes prior to $\mathrm{GA}_{3}$ plus CS pretreatment of intact seeds improved seed germination than CS applied alone. Also, the removal of seed endocarp in combination with CS pretreatment significantly increased germination. Germination of seeds without endocarp was further increased when $\mathrm{GA}_{3}$ was applied. Our results indicate that the endocarp plays a significant role in $P$. mahaleb seed dormancy.

For large amounts of $P$. mahaleb seeds, the removal of endocarp without damages to the embryo is practically difficult; hence, the application of exogenous $\mathrm{GA}_{3}$ during the CS of seeds (with endocarp) is proposed as an effective pretreatment in nurseries to enhance seed germination.

\section{References}

Al-Absi KM (2010). The effects of different pre-sowing seed treatments on breaking the dormancy of mahaleb cherries, Prunus mahaleb L. seeds. Seed Sci Technol 38:332-340.

Baskin CC, Baskin JM (1998). Seeds: Ecology, Biogeography, and Evolution of Dormancy and Germination. Academic Press, San Diego, 666 p.

Browicz K (1982). Chronology of trees and shrubs in southwest Asia and adjacent regions. Vol. 1. Polish Scientific Publishers, Warszawa, Poland, 172 p.

Carpita NC, Skaria A, Barnett JP, Dunlap JR (1983). Cold stratification and growth of radicles of loblolly pine (Pinus taeda) embryos. Physiol Plant 59:601-606.

Cetinbas M, Koyuncu F (2006). Improving germination of Prunus avium L. seeds by gibberelic acid, potassium and thiourea. HorticSci 33(3):119-123.

Chen S, Chien C, Chung J, Yang Y, Kuo S (2007). Dormancybreak and germination in seeds of Prunus campanulata (Rosaceae): role of covering layers and changes in concentration of abscisic acid and gibberellins. Seed Sci Res 17:21-32.

Dirr MA, Heuser CWJ (1987). The reference manual of woody plant propagation: from seed to tissue culture. Varsity Press Inc., Athens, Georgia, 239 p.

Ellis RH, Roberts EH (1981). The quantification of ageing and survival in orthodox seeds. Seed Sci Technol 9:373-409.

Gercekcioglu R, Cekic C (1999). The effects of some treatments on germination of mahaleb (Prunus mahaleb L.) seeds. Turkish J Agric Forestry 23:145-150.

Garcia-Gusano M, Martinez-Gomez P, Dicenta F (2004). Breaking seed dormancy in almond (Prunus dulcis (Mill.) D.A. Webb). Sci Hortic 99:363-370.

Ghayyad M, Kurbysa M, Napolsy G (2010). Effect of endocarp removal, gibberelline, stratification and sulfuric acid on germination of Mahaleb (Prunus mahaleb L.) seeds. Am-Eur J Agric Environ Sci 9(2):163-168.

Grisez TJ, Barbour JR, Karrfalt RP (2008). Prunus L. cherry, peach and plum, 875-890 p. In: Bonner FT, Karrfalt RP (Eds.). Woody Plant Seed Manual. Agriculture Handbook No. 727, USDA Forest Service, Washington, DC.

Iliev N, Petrakieva A, Milev M (2012). Seed dormancy breaking of wild cherry (Prunus avium L.) seeds. Forestry Ideas 17 (1):28-36.

Imani A, Rasouli M, Tavakoli R, Zarifi E, Fatahi R, BarbaEspín G, Martínez-Gómez P (2011). Optimization of seed germination in Prunus species combining hydrogen peroxide or gibberellic acid pre-treatments with stratification. Seed Sci Technol 39(1):204-207.

International Seed Testing Association (ISTA) (1999). International rules for seed testing. Seed Sci Technol 27 Supplement, $333 \mathrm{p}$.

Jordano P, Schupp EW (2000). Seed disperser effectiveness: the quantity component and patterns of seed rain for Prunus mahaleb. Ecol Monographs 70(4):591-615.

Karam NS, Al-Salem MM (2001). Breaking Dormancy in Arbutus andrachne L. by Stratification and Gibberellic acid. Seed Sci Technol 29:51-56.

Klockars A, Sax G (1986). Multiple Comparisons. Newbury 
Park, California: Sage Publications, 87 p.

Kollmann J, Pflugshaupt K (2005). Population structure of a freshly-fruited species at its range edge - the case of Prunus mahaleb L. in northern Switzerland. Bot Helvetica 115:4961.

Lockley GC (1980). Germination of chokecherry (Prunus virginiana) seeds. Seed Sci Technol 8(3):237-244.

Macdonald B (2006). Practical woody plant propagation for nursery growers. Timber Press Inc., Portland, OR, 669 p.

Martínez-Gómez P, Dicenta F (2001). Mechanisms of dormancy in seeds of peach (Prunus persica (L.) Batsch) cv. 'GF305'. Sci Hortic 91:51-58.

Mehanna HT, Martin GC (1985). Effect of seed coat on peach seed germination. Sci Hortic 25:247-254.

Nikolaeva MG (1969). Physiology of deep dormancy in seeds. Izdatel'stvo "Nauka", Leningrad. (Translated from Russian to English by Z. Shapiro, National Science Foundation, Washington, DC).

Nikolaeva MG (1977). Factors controlling the seed dormancy pattern, 51-74 p. In: Khan AA (Ed.) The physiology and biochemistry of seed dormancy and germination. NorthHolland, Amsterdam/New York.

Patton CA, Ranney TG, Burton JD, Walgenbach JF (1997). Natural pest resistance of Prunus taxa to feeding by adult Japanese beetles: Role of endogenous allelochemicals in host plant resistance. J Am Soc Hortic Sci 122(5):668-672.

Piotto B, Bartolini G, Bussotti F, Asensio AAC, Garcia C, Chessa I, Ciccarese C, Ciccarese L, Crosti R, Cullum FJ, Noi AD, Garcia-Fayos P, Lambardi M, Lisci M, Lucci S, Melini S, Reinoso JCM, Murranca S, Nieddu G, Pacini E, Pagni G, Patumi M, Garcia FP, Piccini C, Rossetto M, Tranne G, Tylkowski T (2003). Fact Sheets on the Propagation of Mediterranean Trees and Shrubs from Seed, 11-51 p. In: Piotto B, Noi AD (Eds). Seed Propagation of Mediterranean Trees and Shrubs. APAT, Roma.

Pipinis E, Milios E, Kiamos N, Mavrokordopoulou O, Smiris P (2012). Effects of stratification and pretreatment with gibberellic acid on seed germination of two Carpinus species. Seed Sci Technol 40:21-31.
Pipinis E, Milios E, Smiris P (2011a). Effect of sulphuric acid scarification, cold moist stratification and gibberellic acid on germination of Paliurus spina-christi Mill. seeds. Forestry Ideas 17(1):45-52.

Pipinis E, Milios E, Smiris P, Gioumousidis C (2011b). Effect of acid scarification and cold moist stratification on germination of Cercis siliquastrum L. Turkish J Agric Forestry 35(3):259264.

Rascio N, Mariani P, Dalla Vecchia F, La Roccha N, Profumo P, Gastaldo P (1998). Effects of seed chilling or GA, supply on dormancy breaking and plantlet growth in Cercis siliquastrum L. Plant Growth Regul 25(1):53-61.

Sacheti U, Al-Rawahy SH (1998). The effects of various pretreatments on the germination of important leguminous shrub-tree species of the Sultanate of Oman. Seed Sci Technol 26:691-699.

Smiris P, Pipinis E, Aslanidou M, Mavrokordopoulou O, Milios E, Kouridakis A (2006). Germination study on Arbutus unedo L. (Ericaceae) and Podocytisus caramanicus Boiss. \& Heldr (Fabaceae). J Biol Res 5:85-91.

Snedecor GW, Cochran WC (1980). Statistical methods. Seventh edition. The Iowa State University Press. Ames. Iowa, $507 \mathrm{p}$.

Suszka B (1967).Studies on dormancy and germination of seeds from various species of the genus Prunus L. (in Polish with English summary). Arboretum Kornickie 12:221-282.

Tewari B, Tewari A, Shah S, Pande N, Singh RP (2011). Physical attributes as indicators of seed maturity and germination enhancement in Himalayan Wild Cherry (Prunus cerasoides D. Don.). New Forests 41:139-146.

Young JA, Young CG (1992). Seeds of woody plants in North America Dioscorides. Portland, Oregon.

Zeinalabedini M, Majourhat K, Khayam-Nekoui M, Hernández JA, Martínez-Gómez P (2009). Breaking seed dormancy in long-term stored seeds from Iranian wild almond species. Seed Sci Technol 37(2):267-275. 